\title{
A rare cause of postpartum headache
}

\author{
Nayantara Bijral, ${ }^{1}$ Imran Qureshi, ${ }^{2}$ Aisha Hameed ${ }^{3}$
}

'Obstetrics and Gynaecology, Princess Royal University Hospital, Orpington, UK 2Department of Radiology, Princess Royal University Hospital, Orpington, UK ${ }^{3}$ Obstetrics and Gynaecology, Princess Royal University Hospital, Orpington, UK

Correspondence to Miss Nayantara Bijral, nayantara.bijral1@nhs.net

All authors contributed equally to this paper.

Accepted 6 February 2018

Check for updates

To cite: Bijral N, Qureshi I, Hameed A. BMJ Case Rep Published Online First: [please include Day Month Year]. doi:10.1136/bcr-2017223048

\section{SUMMARY}

Postpartum women can develop headache, and their assessment requires a thorough and multidisciplinary approach. If the headache is unresponsive to treatment and accompanied by neurological deficit, neuroimaging needs to be undertaken to rule out other life-threatening causes. ${ }^{1}$

We present a case of 35-year-old woman with preeclampsia and diet-controlled gestational diabetes mellitus, who had normal vaginal delivery at 40 weeks. She had an epidural analgesia for pain relief during labour, but had inadvertent dural puncture during the procedure and developed headache 24 hours after delivery. The headache was managed conservatively and she was discharged home, but was readmitted 8 days later with worsening headache. The headache was postural on admission but became continuous, developed neurological symptoms in the form of ataxic hemiparesis and convulsions. After neuroimaging, she was found to have cerebral venous sinus thrombosis. She was commenced on anticoagulants and anticonvulsants and made a complete recovery.

\section{BACKGROUND}

Majority of headaches in the postpartum period are primary like migraine and tension-type headache but secondary causes like stroke, intracranial haematomas, meningitis, cerebral tumours or pre-eclampsia also need to be considered. The epidural analgesia is a well-accepted mode of pain relief during labour. Although it is not without complications, one of the most common being accidental dural puncture, which can cause severe headache in the postpartum period. ${ }^{2}$ But if postdural puncture headache (PDPH) is left untreated, it can cause intracranial hypotension and lead to serious complication like cerebral venous sinus thrombosis (CVST). Our patient was being treated for PDPH, but later the character of headache changed along with development of neurological symptoms. Neuroimaging and multidisciplinary team involvement led to an accurate diagnosis and initiation of treatment in an appropriate manner. The patient made an uneventful recovery and was discharged home.

This case is being presented, as dural puncture during epidural analgesia led to PDPH and later contributed to the development of CVST.

\section{CASE PRESENTATION}

A 35-year-old Caucasian Para 1 woman, with diet-controlled gestational diabetes mellitus and mild pre-eclampsia, had a normal vaginal delivery at
40 weeks. She had epidural analgesia administered during labour, with inadvertent dural puncture during epidural insertion. On second postpartum day, she developed symptoms of occipital headache which improved on lying down.

A diagnosis of PDPH was made, which was treated conservatively with fluids, oral analgesia and bed rest. Her symptoms improved and she was discharged home. She was advised to continue with the above management and advised to return to the hospital if her symptoms of headache worsened or any other concerns

She was readmitted 8 days after delivery with worsening headache, which was still postural on admission, but lost its postural character the following day and became continuous. At that stage, PDPH and pre-eclampsia were considered as differential diagnosis, but few hours later, she developed slurred speech and weakness of left side of the body. She was reviewed by the neurologist, and her neurological examination revealed Glasgow Coma Scale (GCS) of $15 / 15$, with left sidedinconsistent cerebellar signs. The non-contrast CT head showed a high attenuation area in the superior sagittal sinus suspicious of thrombosis (figure 1) and CT venogram confirmed the diagnosis of CVST within superior cerebral veins overlying the frontal lobe (figures 2-4). Reconstruction 3D venogram (figures 5 and 6 ) also shows thrombus in anterior part of superior sagittal sinus. Later, she had an episode of tonic clonic seizures with left arm weakness which lasted for about 4 minutes. She was given intravenous $1000 \mathrm{mg}$ levetiracetam and $2 \mathrm{mg}$ lorazepam as a stat dose. Her GCS after the event was 15/15 with no focal neurological signs. A repeat CT scan confirmed the findings of superior sagittal sinus thrombosis, with $8 \mathrm{~mm}$ deep subdural effusion. There was no evidence of acute intra-axial haemorrhage or acute infarct. Laboratory tests including her platelet count, protein $\mathrm{C}$, protein $\mathrm{S}$ and antithrombin concentrations were within normal limits. There was no laboratory evidence of autoantibodies, lupus anticoagulant and antiphospholipid antibody.

\section{TREATMENT}

Our patient was treated by anticoagulation with therapeutic dose of subcutaneous low-molecular-weight heparin, followed by a 6 -month course of oral coumadin. Antiepileptic medication levetiracetam was prescribed for seizure control. Her headache was controlled with oral analgesia.

\section{OUTCOME AND FOLLOW-UP}

The patient was discharged home on the 16th postpartum day. Her headache resolved completely. At a 6-month follow-up, the patient was asymptomatic 


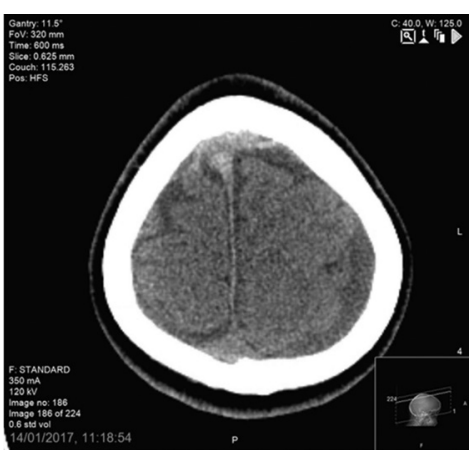

Figure 1 Non-contrast CT head showing high attenuation area in superior sagittal sinus over the frontal lobe in an axial image.

with no headaches or neurological sequelae and oral coumadin was discontinued.

\section{DISCUSSION}

In the most recent third triennial confidential enquiry into maternal deaths, Mothers and Babies: Reducing Risk through Audits and Confidential Enquiries across the UK (MBRRACE), ${ }^{3}$ thrombosis and thromboembolism remain the leading causes of direct maternal death, during and up to 6 weeks after the end of pregnancy, at the rate of 1.01 per 100,000 maternities. In this report, eight women died of cerebral vein thrombosis, of which three were late deaths. It is recommended that severe persistent headache must be considered a warning for imperative neuroimaging, so that thrombosis could be identified and anticoagulation could be initiated promptly.

Headache in the postpartum period can have a varied aetiology. PDPH following epidural insertion is a known complication of labour analgesia among women who had accidental dural puncture. Headache is also the most common symptom of $\mathrm{CVST}^{4}$ and, in perspective of accidental dural puncture, can consequently make immediate identification challenging. The incidence of peripartum and postpartum sinus thrombosis is about 12 per 100000100,000 deliveries. $^{5}$

The cause of CVST after dural puncture is complex. The risk factors for postpartum cerebral venous thrombosis after dural puncture are linked to Virchow's triad, comprising stasis of the blood, changes in the vessel wall and changes in the composition of blood. ${ }^{6}$ First, the loss of cerebrospinal fluid (CSF) after dural puncture decreases intracranial pressure, which leads to compensatory cerebral venous and arterial dilatation (Monro-Kellie hypothesis). ${ }^{7}$ This reduces the venous blood flow velocity in dural sinuses by almost $50 \%,{ }^{8}$ following lumbar puncture.

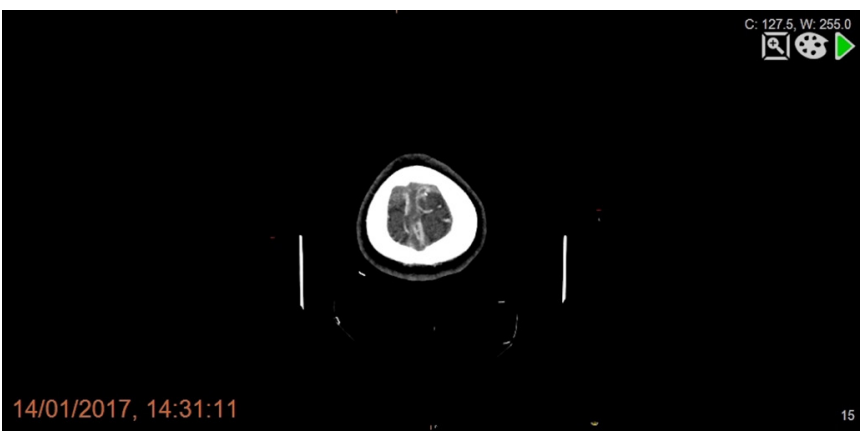

Figure 2 CT venogram showing filling defect in the anterior portion of superior sagittal sinus overlying the frontal lobes in an axial view.

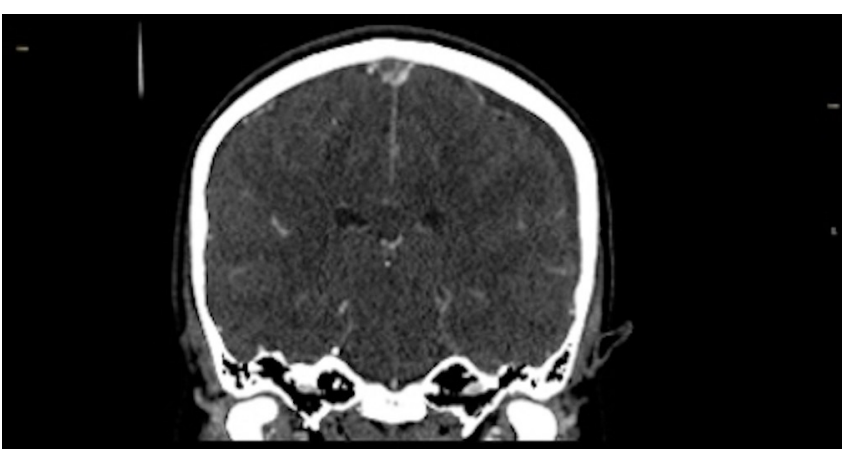

Figure 3 CT venogram showing filling defect in the anterior portion of superior sagittal sinus in a coronal view.

Second, the pull on the cerebral vessels by a negative spinalcranial pressure gradient makes the venous endothelium prone to damage. ${ }^{910}$ Third, the blood viscosity in the cerebral venous sinuses increases, due to reduction in drawing up of CSF into the sinuses, along with hypercoagulable state of pregnancy due to increased platelet adhesions and increase in clotting factors (fibrinogen and factors 7,8 and 10). The reduced blood velocity, vessel wall damage and increased viscosity can activate the thrombotic cascade leading to thrombosis of cerebral venous sinuses. ${ }^{11}$

There have been 30 published case reports, including 7 postpartum cases, which have shown that CVST is a recognised complication of dural puncture.

Kate et al reported a 31-year-old postpartum woman who had caesarean section under spinal anaesthesia and presented with headache followed by convulsions. MR venography showed cortical vein and partial superior sagittal sinus thrombosis, and prothrombotic workup showed proteins $\mathrm{C}$ and $\mathrm{S}$ deficiency. ${ }^{12}$

Stocks et al reported a patient with cortical vein thrombosis in a primigravida, who had a dural puncture during two attempts at epidural and developed occipital headache which was relieved on lying down. But unlike our case, she had two epidural blood patches on day 2 and 4 post partum, and returned with worsening headache and grand mal seizures on day 5. An MRI confirmed the diagnosis of cortical vein thrombosis. A lumbar puncture revealed raised protein and white cell count with xanthochromia. In this case despite the presence of cortical vein thrombosis, the patient was not anticoagulated

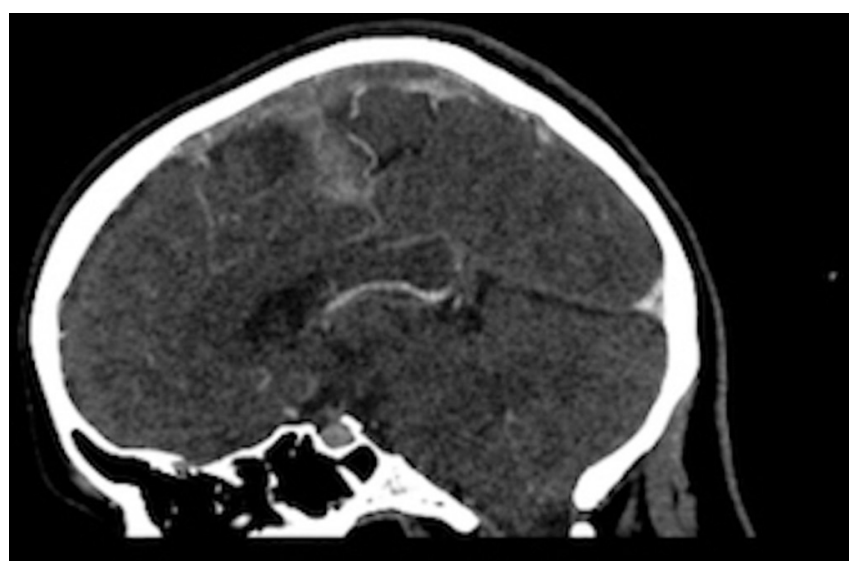

Figure 4 CT venogram showing filling defect in the anterior portion of superior sagittal sinus in a sagittal view. 


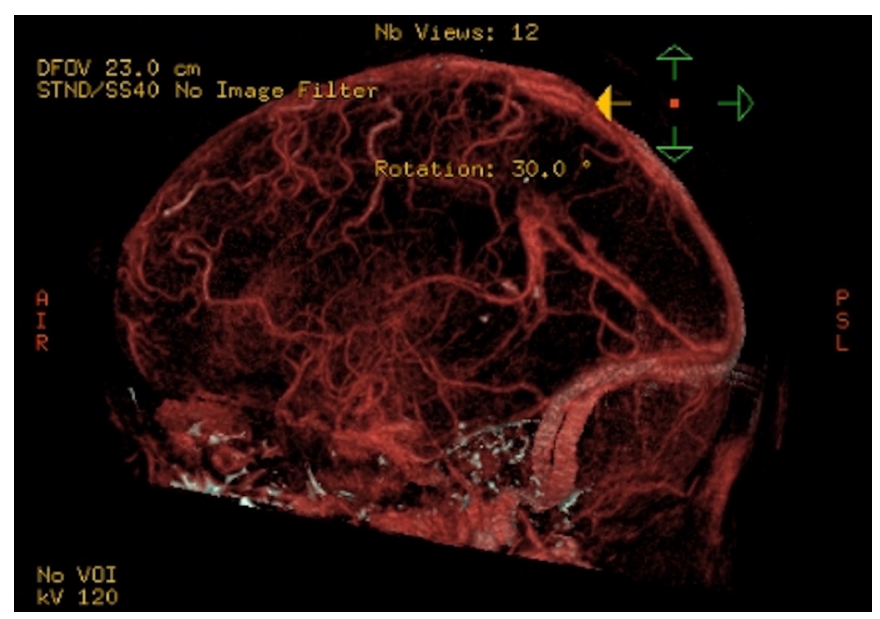

Figure 5 3D venogram showing filling defect in superior sagittal sinus (view 1).

due to xanthochromia, but treated with fluids, analgesics and phenytoin. ${ }^{13}$

Dural puncture seems to trigger CVST particularly in patients with predisposing disorders. A total of 10,740 cases registered in tertiary-care neurology clinic stroke database were reviewed retrospectively to see frequency of CVST following a recent dural puncture. Forty-six patients diagnosed with CVST were reanalysed, and it was found that 9 patients $(19.6 \%)$ had a recent dural puncture before the onset of the symptoms. Five of them were pregnant and all patients had received spinal anaesthesia for caesarean section, but it was found that all of them had an additional risk factor (three protein $\mathrm{S}$ deficiency and two antithrombin deficiency). ${ }^{14}$

Our patient had normal thrombophilia screening and prothrombotic disorders were excluded. She was anticoagulated to prevent the thrombus growth and facilitate recanalisation. There is a probability of spontaneous intracranial bleeding with anticoagulants. However, European Federation of Neurological

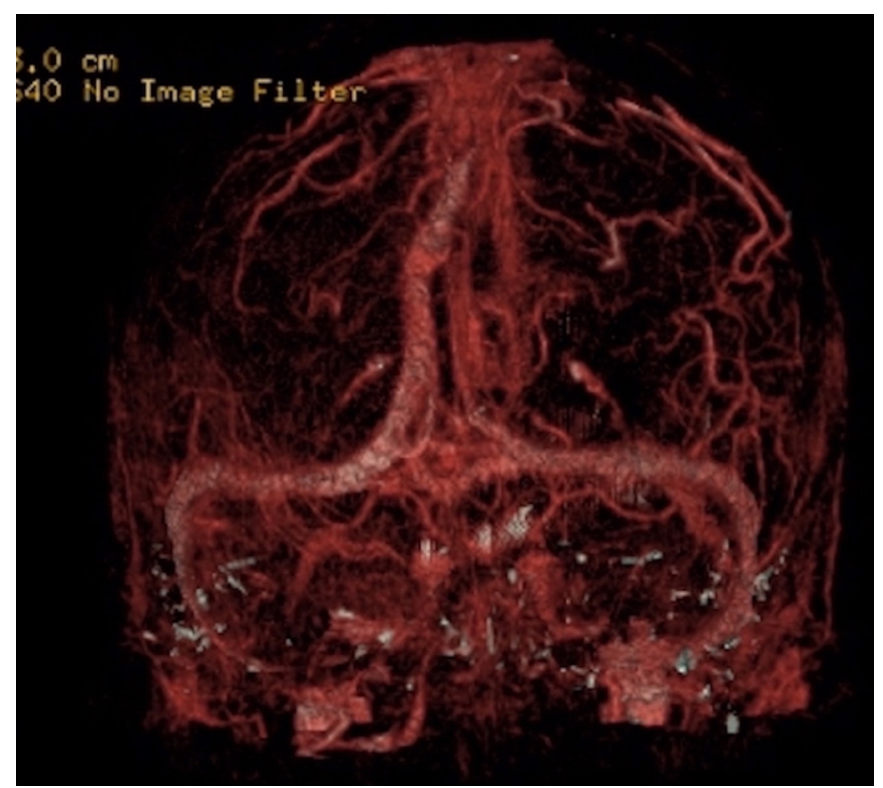

Figure 6 3D venogram showing filling defect in superior sagittal sinus (view 2).
Societies (EFNS) have suggested that it is safe and effective in treatment of CVST. ${ }^{15}$

To summarise, we should consider other intracranial pathology in the differential diagnosis of a patient with persistent postpartum headache, even in a patient with documented inadvertent dural puncture.

\section{Learning points}

- Inadvertent dural puncture during epidural insertion is considered a risk factor for intracranial hypotension.

- Cerebral venous sinus thrombosis should be considered in the differential diagnosis in postpartum women, with history of headache after spinal and/or epidural analgesia.

- There should be low threshold for diagnostic imaging, especially if headache in postpartum period persists or changes its character.

- Utilisation of multidisciplinary team, involving neurologists and a radiologist, can enable an accurate diagnosis and initiation of early treatment can prevent serious neurological sequelae.

Contributors NB: wrote the manuscript and performed literature search. IQ and AH: participated in literature search and final revision of the manuscript. All authors have approved the final version to be published.

Funding This research received no specific grant from any funding agency in the public, commercial or not-for-profit sectors.

Competing interests None declared.

Patient consent Obtained.

Provenance and peer review Not commissioned; externally peer reviewed.

(c) BMJ Publishing Group Ltd (unless otherwise stated in the text of the article) 2018. All rights reserved. No commercial use is permitted unless otherwise expressly granted.

\section{REFERENCES}

1 Stella $\mathrm{CL}$, Jodicke CD, How HY, et al. Postpartum headache: is your work-up complete? Am J Obstet Gynecol 2007;196:e1-7:318.e1-318.e7.

2 Goldszmidt E, Kern R, Chaput A, et al. The incidence and etiology of postpartum headaches: a prospective cohort study. Can J Anaesth 2005;52:971-7.

3 MBRRACE-UK. Knight M, Kenyon S, Brocklehurst P, Neilson J, Shakespeare J, et al. eds. Saving Lives, Improving Mothers' Care - Surveillance of maternal deaths in the UK 2012-14 and lessons learned to inform maternity care from the UK and Ireland Confidential Enquiries into Maternal Deaths and Morbidity 2009-14, 2014.

4 Anand N, Chan C, Wang NE. Cerebral venous thrombosis: a case report. J Emerg Med 2009:36:132-7.

5 Lanska DJ, Kryscio RJ. Risk factors for peripartum and postpartum stroke and intracranial venous thrombosis. Stroke 2000;31:1274-82.

6 Caso V, Agnelli G. Paciaroni M: Handbook on cerebral venous thrombosis.basil. Karger 2008;23:23-54.

7 Mokri B. The Monro-Kellie hypothesis: applications in CSF volume depletion. Neurology 2001;56:1746-8.

8 Canhão P, Batista P, Falcão F. Lumbar puncture and dural sinus thrombosis-a causal or casual association? Cerebrovasc Dis 2005;19:53-6.

9 Wilder-Smith E. Ingrid Kothbauer-Margreiter, Bernhard Lämmle, Matthias Sturzenegger, Christoph Ozdoba, Simon P Hauser: Dural puncture and activated protein $C$ resistance: risk factors for cerebral venous sinus thrombosis. Journal of Neurology, Neurosurgery, and Psychiatry 1997;63:351-6.

10 Stam J. Thrombosis of the cerebral veins and sinuses. N Engl J Med 2005;352:1791-8

11 Bagot CN. Virchow and his triad. British Journal of Haematology 2008;143:180-90.

12 Kate MP, Thomas B, Sylaja PN. Cerebral venous thrombosis in post-lumbar puncture intracranial hypotension: case report and review of literature. F1000Res 2014:3:41. (10.12688/f1000research.3-41. v1).

13 Stocks GM, Wooller DJ, Young JM, et al. Postpartum headache after epidural blood patch: investigation and diagnosis. Br J Anaesth 2000;84:407-10.

14 Guner D, Tiftikcioglu BI, Uludag IF, et al. Dural puncture: an overlooked cause of cerebral venous thrombosis. Acta Neurol Belg 2015;115:53-7.

15 Einhaupl K, Stam J, Bousser MG, et al. European Federation of Neurological Societies. EFNS guideline on the treatment. 
Copyright 2018 BMJ Publishing Group. All rights reserved. For permission to reuse any of this content visit http://group.bmj.com/group/rights-licensing/permissions.

BMJ Case Report Fellows may re-use this article for personal use and teaching without any further permission.

Become a Fellow of BMJ Case Reports today and you can:

- Submit as many cases as you like

- Enjoy fast sympathetic peer review and rapid publication of accepted articles

- Access all the published articles

- Re-use any of the published material for personal use and teaching without further permission

For information on Institutional Fellowships contact consortiasales@bmjgroup.com

Visit casereports.bmj.com for more articles like this and to become a Fellow 